\title{
Thermodynamic Evaluation of Carbide Precipitates in 2.25Cr-1.0Mo Steel for Determination of Service Degradation
}

\author{
Bojan A. Marinkovic, Roberto R. de Avillez*, \\ Simone Kessler Barros, Fernando C. Rizzo Assunção \\ Pontifícia Universidade Católica do Rio de Janeiro \\ Departamento de Ciência dos Materiais e Metalurgia, 22453-900 Rio de Janeiro - RJ, Brazil
}

Received: April 02, 2002; Revised: September 13, 2002

\begin{abstract}
The $2.25 \mathrm{Cr}-1.0 \mathrm{Mo}$ steel is widely used in petroleum refining units, for example, in pressure vessels, working under severe operational conditions. Due to the high temperatures of some processes, many phenomena such as precipitation of carbides and their coarsening occur during service, resulting in changes of material microstructure. Such changes may modify the mechanical properties, which are responsible for the performance of the pressure vessels.
\end{abstract}

Using a software for thermodynamic calculations, the thermodynamically stable carbides over the temperature range of interest $(700-1040 \mathrm{~K})$ were evaluated, supposing ferrite as the original microstructure. The theoretical carbide nucleation sequence was also established. Moreover, the theoretical amount of thermodynamically stable carbides and the fraction of $\mathrm{Fe}, \mathrm{Cr}$ and $\mathrm{Mo}$ in the metallic sublattice of $\mathrm{M}_{23} \mathrm{C}_{6}$ were determined as a function of temperature.

These theoretical calculations were compared to some experimental results on carbide precipitation in the $2.25 \mathrm{Cr}-1.0 \mathrm{Mo}$ steel and two approaches for evaluating the service degradation were proposed. The first one is based on the amount of precipitated $\mathrm{M}_{23} \mathrm{C}_{6}$ and the other on the $\mathrm{Fe} / \mathrm{Cr}$ ratio in the $\mathrm{M}_{23} \mathrm{C}_{6}$ carbide.

Keywords: 2.25Cr-1Mo steel, carbides, service degradation, thermodynamic stability, Thermo-Calc

\section{Introduction}

Pressure vessels are used in the petroleum industry in conditions of high temperatures and partial pressures of hydrogen ${ }^{1,2}$. These two factors together with long times of utilization could lead to, at least, two degradation processes of the pressure vessel walls: $2.25 \mathrm{Cr}-1.0 \mathrm{Mo}$ steel microstructural changes and fragilization by hydrogen ${ }^{3}$.

The microstructural changes are associated with precipitation of carbides and their coarsening ${ }^{4,5}$ and they are very important due to their direct influence on the mechanical properties of the pressure vessel walls ${ }^{6}$. Therefore, the focus of the present theoretical study is on the computer evaluation of the theoretical carbide nucleation sequence as well as the type and the amount of the thermodynamically stable carbides in the temperature range of interest (700-1040 K) for pressure vessels made of ferritic $2.25 \mathrm{Cr}-1.0 \mathrm{Mo}$ steel ${ }^{7}$. Furthermore, the theoretical amount of the thermodynamically stable carbides and the fraction of metals ( $\mathrm{Fe}, \mathrm{Cr}$ and $\mathrm{Mo}$ ) in the metal sub-lattice are evaluated for the same temperature range. All calculations were done supposing ferrite as the original microstructure. The software used in these calculations was THERMO-CALC ${ }^{8-10}$.

The theoretical calculations, carried out in this manner, were compared with some experimental results ${ }^{7,11-13}$ available in the literature. The intention is to establish the criteria for evaluation of the ageing process in $2.25 \mathrm{Cr}-1.0 \mathrm{Mo}$ steel.

\section{Theoretical background}

There are seven types of carbides potentially present in the 2.25Cr-1.0Mo steel: $\mathrm{M}_{2} \mathrm{C}, \mathrm{M}_{3} \mathrm{C}, \mathrm{M}_{3} \mathrm{C}_{2}, \mathrm{M}_{5} \mathrm{C}_{2}, \mathrm{M}_{6} \mathrm{C}, \mathrm{M}_{7} \mathrm{C}_{3}$

*e-mail: avillez@dcmm.puc-rio.br 
and $\mathrm{M}_{23} \mathrm{C}_{6}$. The most probable carbide nucleation sequence and the thermodynamically stable carbides have not been established theoretically, yet. The nucleation sequence is important for short time service conditions, while the stable carbides are expected to predominate after long time service.

All theoretical evaluations were based on the calculations of two distinct driving forces. The driving forces for nucleation were calculated as proposed by Hillert ${ }^{9,10}$ and their schematic representation is presented in Fig. 1. The carbide phase with the largest driving force for nucleation in this figure, $\Delta \mathrm{G}^{\beta}$, will be the first one that nucleates.

The second driving force is the one that deals with the thermodynamic stability of carbides. For the phases which are in thermodynamic equilibrium this driving force has the value zero and it is negative for unstable conditions. The schematic representation of this driving force is presented in Fig. 2.

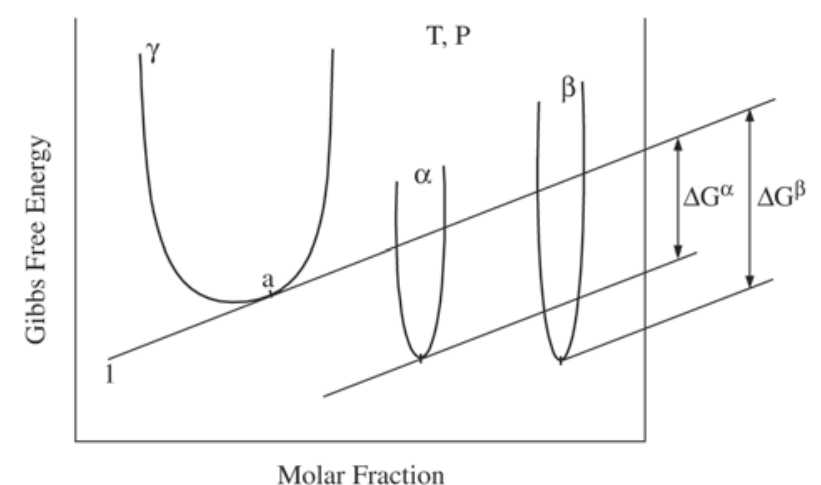

Figure 1. Schematic representation of the driving forces of nucleation.

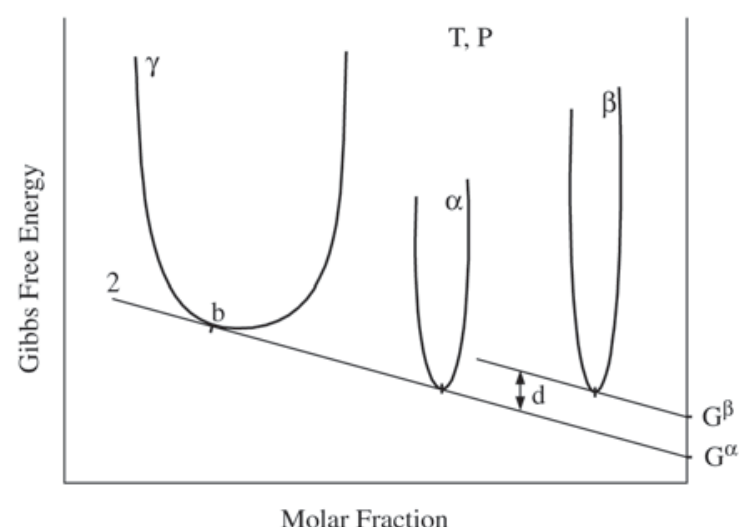

Figure 2. Schematic representation of the driving forces of the thermodynamical stability.
It should be mentioned that a realistic chemical composition of a typical $2.25 \mathrm{Cr}-1.0 \mathrm{Mo}$ steel was used for all calculations, Table 1 . The thermodynamic properties of the elements and the binary phases were described according to the CALPHAD approach ${ }^{14}$ and given in the THERMOCALC database (SSOL).

\section{Results and Discussion}

\subsection{Theoretical Calculations}

The Fig. 3 shows the driving forces for the nucleation of the carbides in a $2.25 \mathrm{Cr}-1.0 \mathrm{Mo}$ ferrite steel matrix. The nucleation sequence, which occurs in the range between $700-1040 \mathrm{~K}$ is:

$\mathrm{M}_{2} \mathrm{C} \rightarrow \mathrm{M}_{3} \mathrm{C}_{2} \rightarrow \mathrm{M}_{7} \mathrm{C}_{3} \rightarrow \mathrm{M}_{23} \mathrm{C}_{6} \rightarrow \mathrm{M}_{3} \mathrm{C} \rightarrow \mathrm{M}_{6} \mathrm{C} \rightarrow \mathrm{M}_{5} \mathrm{C}_{2}$. If no carbides are precipitated during the pre-processing of the steel, then this should be the most probable nucleation sequence in the temperature range between 700 and $1040 \mathrm{~K}$, usually employed in the pressure vessels.

However, the thermodynamically stable carbide phases in the ferrite matrix are the $\mathrm{M}_{23} \mathrm{C}_{6}$ and $\mathrm{M}_{6} \mathrm{C}$ up to $925 \mathrm{~K}$. Above this temperature, only the $\mathrm{M}_{23} \mathrm{C}_{6}$ carbide remains stable, as shown in Fig. 4. The eventual presence of other carbides in the steel is a clear indication that the stable conditions have not been reached.

The theoretical mass fraction of the thermodynamically stable carbide phases $\left(\mathrm{M}_{23} \mathrm{C}_{6}\right.$ and $\left.\mathrm{M}_{6} \mathrm{C}\right)$ in the ferrite matrix

Table 1. Chemical composition of typical 2.25Cr-1.0Mo Steel.

\begin{tabular}{lcccccc}
\hline Element & $\mathrm{C}$ & $\mathrm{Cr}$ & $\mathrm{Mo}$ & $\mathrm{Mn}$ & $\mathrm{Si}$ & $\mathrm{Ni}$ \\
\hline Weight Percent & 0.15 & 2.262 & 1.15 & 0.66 & 0.30 & 0.20 \\
\hline
\end{tabular}

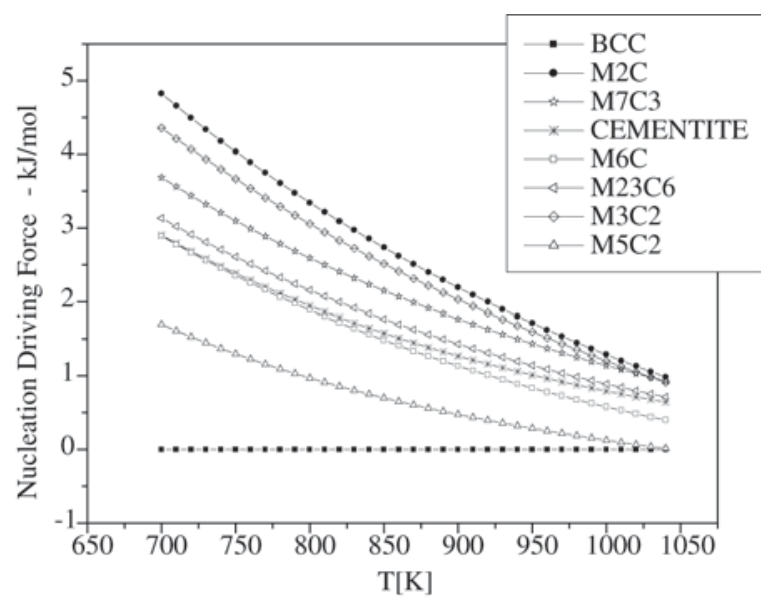

Figure 3. Driving Forces for Nucleation of carbides in a $2.25 \mathrm{Cr}-$ 1.0Mo steel. 


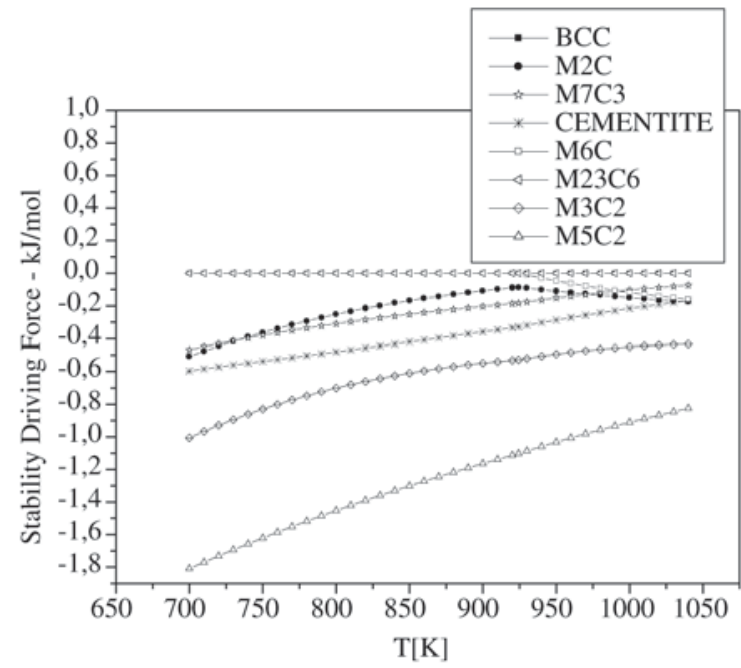

Figure 4. Driving Forces for thermodynamically stable carbides in a $2.25 \mathrm{Cr}-1.0 \mathrm{Mo}$ steel.

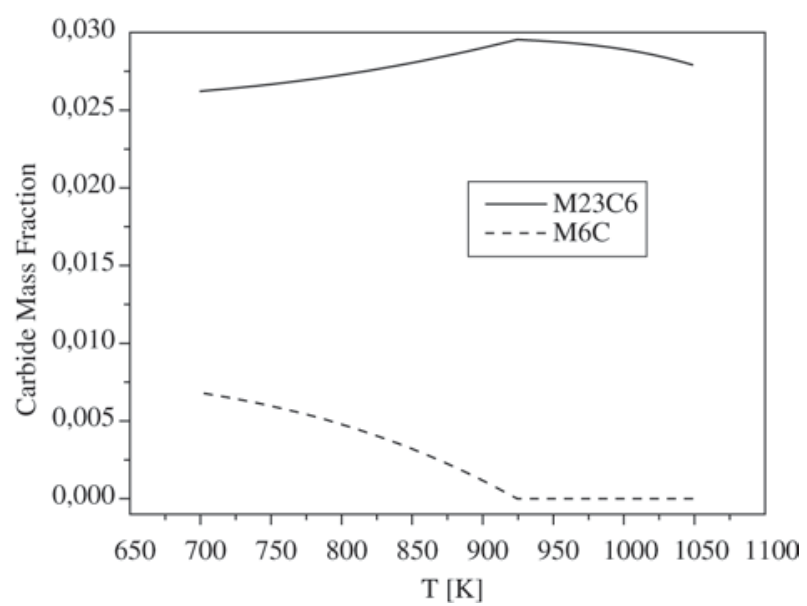

Figure 5. Theoretical mass fraction of the thermodynamically stable carbides $\mathrm{M}_{23} \mathrm{C}_{6}$ and $\mathrm{M}_{6} \mathrm{C}$.

for the $2.25 \mathrm{Cr}-1.0 \mathrm{Mo}$ steel is presented in Fig. 5 for the temperature range between 700 and $1040 \mathrm{~K}$. The $\mathrm{M}_{23} \mathrm{C}_{6}$ predominates over the whole temperature range. The $\mathrm{M}_{23} \mathrm{C}_{6}$ mass fraction changes only slightly as a function of the temperature while the $\mathrm{M}_{6} \mathrm{C}$ mass fraction decreases steadily until this carbide disappears at approximately $925 \mathrm{~K}$.

The equilibrium distribution of metals ( $\mathrm{Fe}, \mathrm{Cr}$ and $\mathrm{Mo}$ ) in the metal sub-lattice was evaluated for the $\mathrm{M}_{23} \mathrm{C}_{6}$ carbide, stable over the temperature range between 700 and $1040 \mathrm{~K}$, Fig. 6. This figure shows that iron and chromium are present in considerable amounts in the metal sublattice of $\mathrm{M}_{23} \mathrm{C}_{6}$ and that there is a significant variation in their quantities as

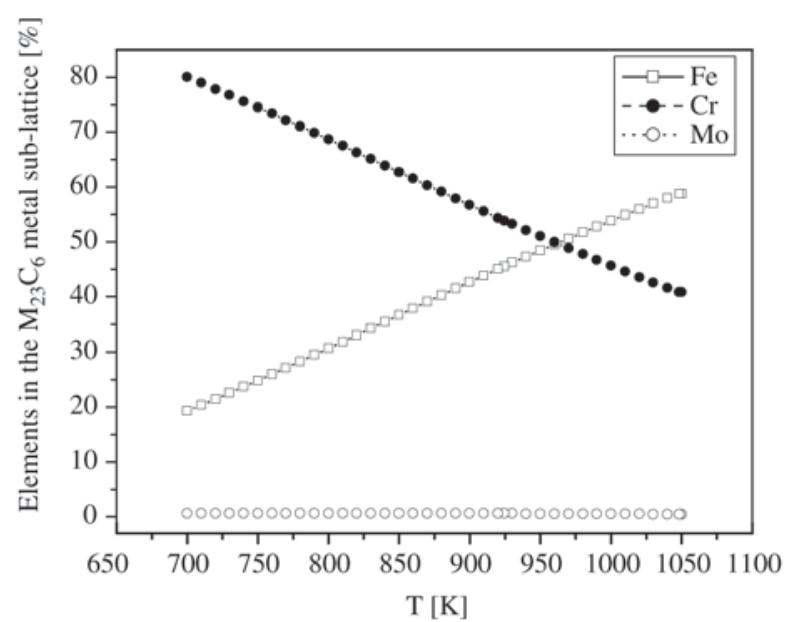

Figure 6. Theoretical content of the metals $\mathrm{Fe}, \mathrm{Cr}$ and $\mathrm{Mo}$ in the metal sublattice of $\mathrm{M}_{23} \mathrm{C}_{6}$.

a function of temperature. Chromium is the most abundant metal up to about $960 \mathrm{~K}$, loosing its preponderant position to iron above this temperature.

\subsection{Comparison with Some Experimental Results}

Yang et.al. ${ }^{11}$ studied $2.25 \mathrm{Cr}-1.0 \mathrm{Mo}$ steel steam pipes without service and after extended service time of 5 and 18 years at the nominal temperature of $815 \mathrm{~K}$ using transmission electron microscopy with energy dispersive spectroscopy. Their results are very consistent with our theoretical calculations. The original microstructure of the steam pipes considered by Yang et.al. ${ }^{11}$ consisted of ferrite and perlite which is similar to that supposed in our evaluations.

One of the principal conclusions of the authors ${ }^{11}$ is that the steam pipes without service exhibit large amounts of $\mathrm{M}_{2} \mathrm{C}$ particles precipitate within the ferrite matrix. However, the 5 years old specimen has the $\mathrm{M}_{7} \mathrm{C}_{3}$ as the dominant carbide. The 18 years old specimen did not show any $\mathrm{M}_{7} \mathrm{C}_{3}$ particles and instead of that the principal carbide in this sample is the $\mathrm{M}_{23} \mathrm{C}_{6}$. The authors also reported on the $\mathrm{Fe}, \mathrm{Cr}$ and Mo composition of the $\mathrm{M}_{23} \mathrm{C}_{6}$ carbide in the 5 and 18 years old samples determined by EDS analysis. They found that the amount of $\mathrm{Fe}$ in the carbide was about 75.6 at $\%$ for the 5 years old steel and it decreased to 43.9 at $\%$ after 18 years. The predicted equilibrium value at $815 \mathrm{~K}$ is around 32 at\% Fe (Fig. 6), suggesting that the steel did not reach the equilibrium condition but was approaching it. It was observed that non-equilibrium $\mathrm{M}_{23} \mathrm{C}_{6}$ carbide particles present in the 5 years old specimen have a predominance of $\mathrm{Fe}$, while the particles of $\mathrm{M}_{23} \mathrm{C}_{6}$ encountered in the 


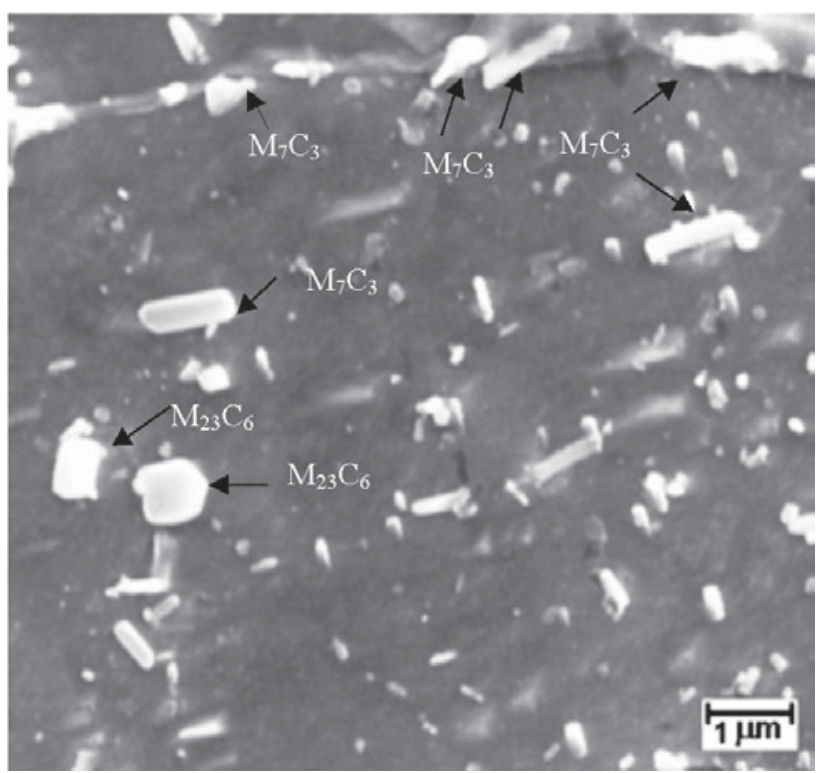

Figure 7. Microstructure of a $2.25 \mathrm{Cr}-1.0 \mathrm{Mo}$ steel from the pressure vessel walls with the service time of 2 years. Carbides are marked by arrows.

18 years old specimen have the predominance of $\mathrm{Cr}$ as it has been predicted by the theoretical calculations for the temperatures below $960 \mathrm{~K}$. The $\mathrm{M}_{6} \mathrm{C}$ carbide was not encountered by Yang et al. ${ }^{11}$, although it was observed by Kurzydlowski and Zielinski ${ }^{12}$ in a similar steel held for 10 years at $793 \mathrm{~K}$.

The present theoretical evaluation of the carbide nucleation sequence, Fig. 3, indicates that the predominant presence of the $\mathrm{M}_{2} \mathrm{C}$ in the new steam pipes and the $\mathrm{M}_{7} \mathrm{C}_{3}$ in the 5 years old specimens are reasonable due to the fact that these carbides are metastable and precede the $\mathrm{M}_{23} \mathrm{C}_{6}$ in the carbide nucleation sequence. The occurrence of the $\mathrm{M}_{2} \mathrm{C}$ in the new steam pipes without service suggests that this carbide precipitation starts during pre-processing of the $2.25 \mathrm{Cr}-1.0 \mathrm{Mo}$ steel.

On the other hand, the predominance of the $\mathrm{M}_{23} \mathrm{C}_{6}$ carbide after 18 years of service is explained by the thermodynamic stability of this carbide, Fig. 4 . The microstructure of this steel is thus approaching the thermodynamically stable conditions, but has not reached it, as indicated by the carbide composition being off the equilibrium value, as previously discussed.

Yang et al. ${ }^{11}$ interpreted the lack of $\mathrm{M}_{6} \mathrm{C}$ particles in the 18 years old specimen as a consequence of the low $\mathrm{Si}$ content in the investigated $2.25 \mathrm{Cr}-1.0 \mathrm{Mo}$ steel steam pipes. In fact, another explanation could be considered. Namely, the calculation of the quantitative relation between two sta- ble carbides $\mathrm{M}_{23} \mathrm{C}_{6}$ and $\mathrm{M}_{6} \mathrm{C}$, Fig. 5, at the $815 \mathrm{~K}$, reveals that the theoretical content of the $\mathrm{M}_{6} \mathrm{C}$ is very low. Therefore, it is possible that the $\mathrm{M}_{6} \mathrm{C}$ particles are present in the $2.25 \mathrm{Cr}-1.0 \mathrm{Mo}$ steel steam pipes after 18 years of service at high temperature conditions, but in very small percentage. It is worth to be mentioned that the $815 \mathrm{~K}$ was the nominal temperature in the $2.25 \mathrm{Cr}-1.0 \mathrm{Mo}$ steel steam pipes during service. Thus, even small variation to higher temperatures would reduce, even more, the estimated percentage of $\mathrm{M}_{6} \mathrm{C}$.

The research conducted by Kessler ${ }^{7}$ dealt with the microstructural degradation of $2.25 \mathrm{Cr}-1.0 \mathrm{Mo}$ steel in the pressure vessel walls with the service time of 2 years. Four types of carbides, $\mathrm{M}_{2} \mathrm{C}, \mathrm{M}_{7} \mathrm{C}_{3}, \mathrm{M}_{3} \mathrm{C}$ and $\mathrm{M}_{23} \mathrm{C}_{6}$ were determined by $\mathrm{X}$-ray diffraction analysis of the extracted precipitates. Figure 7 shows the $\mathrm{M}_{7} \mathrm{C}_{3}$ and $\mathrm{M}_{23} \mathrm{C}_{6}$ carbides that were also identified through morphology and composition analyses using scanning electron microscopy with energy dispersive spectroscopy. The presence of all these carbides could be understood as a metastable microstructure within the context of carbide precipitation discussed here.

Parvathavarthini et al. ${ }^{13}$ studied the microstructure of $2.25 \mathrm{Cr}-1.0 \mathrm{Mo}$ ferritic steel, heat treated at $973 \mathrm{~K}$ and $1023 \mathrm{~K}$ for one and eight hours, after the austenitization at $1193 \mathrm{~K}$. Their samples heat treated at $973 \mathrm{~K}$ for one hour preserved the $\mathrm{M}_{3} \mathrm{C}$ carbide precipitated during normalization from $1193 \mathrm{~K}$ and formed two new carbides, $\mathrm{M}_{2} \mathrm{C}$ and $\mathrm{M}_{3} \mathrm{C}_{7}$. The heat treatment at the higher temperature, $1023 \mathrm{~K}$, for one hour caused the disappearance of the $\mathrm{M}_{3} \mathrm{C}$ and the precipitation of $\mathrm{M}_{2} \mathrm{C}, \mathrm{M}_{7} \mathrm{C}_{3}$ and $\mathrm{M}_{23} \mathrm{C}_{6}$. The $\mathrm{M}_{23} \mathrm{C}_{6}$ carbides formed together with the previously precipitated carbides after eight hours treatment at $973 \mathrm{~K}$, clearly indicating the metastable conditions of the samples. The results of Parvathavarthini et al. ${ }^{13}$ corroborate with the theoretical carbide nucleation sequence established here.

The present results are important for the evaluation of the microstructural degradation of $2.25 \mathrm{Cr}-1.0 \mathrm{Mo}$ steel with original ferrite microstructure and, therefore, the determination of the remaining useful service life. Two approaches could be proposed. The first one is the identification and quantification of carbide phases present. The final stage of degradation should be characterised by a the microstructure dominated by $\mathrm{M}_{23} \mathrm{C}_{6}$ carbide. The second option is to follow the evolution of $\mathrm{Fe} / \mathrm{Cr}$ ratio in the $\mathrm{M}_{23} \mathrm{C}_{6}$ particles. It was showed that for short times the $\mathrm{M}_{23} \mathrm{C}_{6}$ carbide is richer in $\mathrm{Fe}$, but it will enrich in $\mathrm{Cr}$ for very long times in heavily degraded steam pipes. This will hold true for temperatures below $960 \mathrm{~K}$.

\section{Conclusions}

The following theoretical carbide nucleation sequence in the $2.25 \mathrm{Cr}-1.0 \mathrm{Mo}$ steels having ferrite matrix, in the tem- 
perature range of interest for pressure vessels (700-1040 K), was established as:

$\mathrm{M}_{2} \mathrm{C} \rightarrow \mathrm{M}_{3} \mathrm{C}_{2} \rightarrow \mathrm{M}_{7} \mathrm{C}_{3} \rightarrow \mathrm{M}_{23} \mathrm{C}_{6} \rightarrow \mathrm{M}_{3} \mathrm{C} \rightarrow \mathrm{M}_{6} \mathrm{C} \rightarrow \mathrm{M}_{5} \mathrm{C}_{2}$.

The two thermodynamically stable carbides at relevant temperatures for pressure vessel service are $\mathrm{M}_{23} \mathrm{C}_{6}$ and $\mathrm{M}_{6} \mathrm{C}$. The $\mathrm{M}_{6} \mathrm{C}$ phase loses its stability at about $925 \mathrm{~K}$, while $\mathrm{M}_{23} \mathrm{C}_{6}$ retains its stability over the whole temperature range up to $1040 \mathrm{~K}$. Further, $\mathrm{M}_{23} \mathrm{C}_{6}$ is the predominant carbide phase over the temperature range between $700 \mathrm{~K}$ and $1040 \mathrm{~K}$.

The theoretical metal ( $\mathrm{Fe}, \mathrm{Cr}, \mathrm{Mo}$ ) ratio in the $\mathrm{M}_{-23} \mathrm{C}_{6}$ metal sublattice depends on temperature. The predominant element in the metal sub-lattice over the temperature range $700-960 \mathrm{~K}$ is chromium.

Two possible approaches for evaluating the microstructure degradation of $2.25 \mathrm{Cr}-1.0 \mathrm{Mo}$ steel in the steam pipes operating at nominal temperatures below $960 \mathrm{~K}$ have been proposed. The first one is based on the gradual evolution in the amount of the equilibrium $\mathrm{M}_{23} \mathrm{C}_{6}$ carbide. The second possibility is to observe the variation of the $\mathrm{Fe} / \mathrm{Cr}$ ratio in the $\mathrm{M}_{23} \mathrm{C}_{6}$ particles, from the poor to the rich in $\mathrm{Cr}$.

\section{Acknowledgements}

The authors are grateful to CNPq, CAPES and FAPERJ for financial support.

\section{References}

1. Moss, C.J.; Kelly P.M. Fatigue and Fracture Engineering Materials and Structures, v. 17, n. 3, p. 369-380, 1994.

2. Murakami, Y.; Nomura, T.; Watanabe, J. Application of
2,25 Cr-1 Mo Steel for Thick Wall Pressure Vessels, ASTM STP 755, American Society for Testing Materials, p. 383-417, 1982.

3. Furusawa, J.; Watanabe, S. The Sumitomo Search, v. 35, 1987.

4. Inuoe, A.; Masumoto, T. Metallurgical Transactions A, v. 11, p. 739-747, 1980.

5. Thomson, R.C.; Bhadeshia, H.K.D.H. Material Science and Technology, v. 10, p. 193-203, 1994.

6. Lundin, C.D.; Khan, K.K.; Yang. D.; Hilton, S.; Zielke, W. WRC Bulletin, 354, 1990.

7. Kessler, S. MSc Dissertation, DCMM, PUC-Rio de Janeiro, 2000. (in Portuguese).

8. Sundman, B. Thermo-Calc Version L - User's Guide, 1998.

9. Hillert, M. The Uses of Gibbs Free Energy - Composition Diagrams, in the Lectures on the Theory of Phase Transformations, Ed. H.T.Aaronson, The Metals Society of AIME, 1975.

10. Hillert, M. Phase Equilibria, Phase Diagrams and Phase Transformation: A Thermodynamic Basis, Cambridge University Press, 1998.

11. Yang, J.R.; Huang, C.Y.; Yang, C.N.; Horng, J.L. Materials Characterization., v. 30, p. 75-88, 1993.

12. Kurzydlowski, K.J.; Zielinski, W. Metal Science, v. 18, p. 223-224, 1984.

13. Parvathavarthini, N.; Saroja, S.; Dayal, R.K.; Khatak, H.S. J. Nucl. Mater, v. 288, p. 187-196, 2001.

14. Sundman, B.; Jansson, B.; Andersson, J.O. Calphad, v. 9, p. 153-190, 1985. 